Debt Thresholds and Real Exchange Rates: An Emerging Markets Perspective

Vahagn Galstyan \& Adnan Velic

\author{
TEP Working Paper No. 0416
}

March 2016

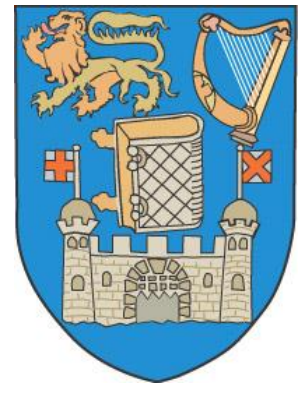

Trinity Economics Papers

Department of Economics

Trinity College Dublin 


\title{
Debt Thresholds and Real Exchange Rates: An Emerging Markets Perspective*
}

\author{
Vahagn Galstyan \\ Adnan Velic \\ Trinity College Dublin \\ Dublin Institute of Technology
}

January 27, 2016

\begin{abstract}
In this paper we empirically analyze nonlinearities in short-run real exchange rate dynamics. Our findings suggest that real exchange rate misalignments are considerably less persistent and more volatile during times of high debt. Assessing the variance of changes in misalignments, we retrieve evidence indicating that the nominal exchange rate and inflation differentials are more important determinants in states of high debt than in states of low debt. Overall, our results imply that nonlinearities have non-negligible implications for the mechanics of real exchange rate adjustment in emerging markets.
\end{abstract}

Keywords: Public debt, External debt, Real exchange rate, Nonlinearities

JEL Codes: F00, F41

*Email: v.galstyan@tcd.ie, adnan.velic@dit.ie. 


\section{Introduction}

Public and external debt have historically played central roles in emerging market crises, often imparting substantial exchange rate effects. As Reinhart and Rogoff (2009) note, emerging market defaults can occur at much lower debt levels that would appear to be quite feasible by the standards of most advanced economies. During times of higher debt close to the default threshold, sharp real exchange rate depreciations arise as debtintolerant locals and foreign investors flee the currency and other local assets, rebalancing their portfolios toward less risky and more liquid securities. Similar adjustments are less frequent in environments of low debt. The goal of this paper is to investigate the empirical relevance of debt for real exchange rate dynamics.

It is widely accepted that high levels of debt can have significant repercussions for the economy. Reinhart and Rogoff (2009), Jorda et al. (2011), Gourinchas and Obstfeld (2012) and Catão and Milesi-Ferretti (2014) provide evidence suggesting that high stocks of external debt enhance the risk of a financial crisis. Krugman (1988) identifies the situation of a "debt overhang" in which the anticipated repayment ability on external debt falls short of the contractual value of debt. A possible implication of this observation is that up to a certain point foreign debt accumulation can promote investment and growth, whereas past that point the debt overhang begins to diminish investors' willingness to supply further capital. This may have negative repercussions for output growth and debt sustainability, in turn putting downward pressure on the real exchange rate. ${ }^{1}$

While these studies suggest potential channels for debt-driven asymmetries in exchange rate adjustment, Galstyan and Velic (2016) emphasize the long-run relation between the level of gross public debt and the real exchange rate. They show that high public debt associated with high levels of distortionary taxation affects the relative supply of goods and services, thus necessitating relative price adjustment for a given relative demand. The sign and magnitude of this adjustment depend on the relative strength of wealth and income effects as well as relative factor intensities.

In this paper we investigate the empirical relevance of debt for exchange rate dynamics using a panel of emerging market economies and relatively novel nonlinear econometric techniques. Our empirical base builds on the fundamental equilibrium exchange rate methodology (Galstyan and Lane 2009; Ricci et al 2013; Galstyan 2015; Galstyan and

\footnotetext{
${ }^{1} \mathrm{~A}$ theoretical model positing the nonlinear impact of foreign borrowing on investment is provided by Cohen (1993). For developing countries, Adam and Bevan (2005) find evidence of threshold effects in the relation between fiscal deficits and growth, with high debt stocks exacerbating the adverse consequences of the former, while the study of Patillo et al. (2011) suggests nonlinear effects of external debt on growth.
} 
Velic 2016). ${ }^{2}$ Adopting a panel-cointegrating framework, we extend the conventional set of controls to include public debt. ${ }^{3}$ Our findings suggest that countries with higher government debt levels tend to have more depreciated exchange rates.

The introduction of debt-contingent short-run nonlinear real exchange rate dynamics in the context of a panel cointegrating setup is the distinguishing other novelty of our methodological approach. ${ }^{4}$ Employing a regime-switching error-correction model, we retrieve evidence of nonlinear real exchange rate adjustment in the short run. In particular, the speed of exchange rate adjustment is found to be faster during episodes of high public or external debt, with misalignments typically characterized by higher volatility and relatively low half-lives across the different specifications. ${ }^{5}$ Decomposing the real exchange rate and examining its underlying components, we also retrieve evidence indicating that nominal exchange rate changes and inflation differentials explain more of the volatility in real exchange rate misalignments during high-debt episodes than during low-debt episodes.

The remainder of the paper is organized as follows. Section 2 provides a description of the empirical framework adopted. Section 3 describes the data. In section 4 we offer some preliminary findings, while in section 5 we discuss the primary panel results. Section 6 describes our findings on the underlying sources of the variability in exchange rate misalignment fluctuations across different states of debt. Lastly, section 7 concludes.

\section{Empirical Approach}

\subsection{Long-Run Equilibrium Relation}

Of primary interest is the misalignment of the real exchange rate from the long-run equilibrium. To construct this benchmark, we first examine the long-run relation between the real exchange rate and a set of fundamentals by estimating the following panel cointe-

\footnotetext{
${ }^{2}$ See Chinn (2012) for a survey on macro approaches to exchange rate determination.

${ }^{3}$ See Appendix A for a proposed mechanism. Pesaran (1997) associates cointegration with the empirical analysis of steady-state relations.

${ }^{4}$ Hansen (1999) first introduced the non-dynamic panel threshold regression model that over time allows discrete shifts in coefficients across regimes. As in the corresponding time series setup, the movement from one regime to another is abrupt and the model implicitly assumes that the different groups of observations are clearly identified and distinguished. Building on this work, González et al. (2005) developed the panel smooth transition regression model that instead facilitates a smooth and gradual transition of coefficients between regimes. Smooth transition models are effectively a generalization of threshold models, and may alternatively be interpreted as allowing for a "continuum" of regimes.

${ }^{5}$ Univariate studies focusing on exchange rate dynamics often seek to incorporate nonlinearities in the adjustment process that are rationalized by the existence of transaction costs, heterogeneous foreign exchange traders or discrepancies in central bank interventions for instance. See Michael et al. (1997) and Taylor et al. (2001).
} 
grating equation

$$
y_{i, t}=\alpha_{i}+\boldsymbol{\beta}^{\prime} \mathbf{x}_{i, t}+\epsilon_{i, t}
$$

where $y_{i, t}$ is the natural logarithm of the real effective exchange rate, $\mathbf{x}_{i, t}$ is the vector of covariates and $\alpha_{i}$ is the country-specific fixed effect. ${ }^{6}$ The $\boldsymbol{\beta}^{\prime}$ vector summarizes the longrun relation between the dependent variable and the vector of explanatory variables. Equation (1) is estimated using the method of fully modified OLS for heterogeneous cointegrated panels à la Pedroni (2000). ${ }^{7}$

In Appendix A we sketch a small model that justifies the set of control variables. In particular, equation (A.12) shows that a positive net foreign asset position, generating a positive wealth transfer from the rest of the world, is associated with an appreciated exchange rate. Higher relative productivity in the traded sector causes an appreciation of the real exchange rate via the Balassa-Samuelson mechanism. Regarding public consumption, for a given level of the tax rate, government spending weighted towards nontraded goods engenders a rise in the relative price of those goods and thus the real exchange rate. Finally, higher public debt is associated with a more depreciated real exchange rate. ${ }^{8}$

Accordingly, relative per capita GDP as a proxy for the relative productivity differential, government expenditure, and gross public debt are used in our study. Regarding the net foreign asset position, we find that the associated parameter estimate is unstable across samples. Consequently, we rely on the steady-state negative link between the trade balance and net foreign asset position, and instead use the former variable as a

\footnotetext{
${ }^{6} \mathrm{An}$ increase in $y_{i, t}$ indicates appreciation. Since the multilateral real exchange rates are index numbers with no natural common anchor across different countries, it is essential to include country-specific fixed effects in the specification.

${ }^{7}$ Fully modified OLS adopts a non-parametric procedure to correct for the endogeneity bias arising from a possible correlation between the unit-root innovations and innovations of the cointegrating equation. In contrast, the panel dynamic OLS estimator uses leads and lags of the first-differenced regressors to tackle the issue. The former estimator is preferred to the latter estimator for two reasons. First, dynamic OLS requires knowledge of the number of the aforementioned leads and lags in order to provide an adequate endogeneity correction. To the best of our knowledge, no established reliable criterion exists on how to determine these numbers. Second, according to Pedroni (2001) and Breitung and Pesaran (2008), fully modified and dynamic OLS possess the same asymptotic distribution and can perform poorly if the number of time periods or observations per cross-sectional unit is less than 20. Since our sample period covers 22 years, fully modified OLS would appear to be a more suitable estimator. We also applied the dynamic OLS estimator with a lead and lag of 1 as a robustness check and found results qualitatively similar to those with fully modified OLS.

${ }^{8}$ In the long run, for a given level of public spending, high public debt is associated with a higher tax rate. A high tax rate, in turn, reduces aggregate labor supply proportionally in both sectors. Due to the fixed factor of production in the nontraded sector however, contraction in the supply of nontraded goods is smaller than the contraction in the supply of traded goods. This increase in the relative supply of nontraded goods causes the relative price of nontraded goods to decline.
} 
regressor with an expected negative sign. ${ }^{9}, 10$ By exerting potential income or wealth effects, a higher terms of trade should cause real exchange rate appreciation. Therefore, it is also included in the analysis. ${ }^{11}$

\subsection{Short-Run Asymmetric Dynamics}

\subsubsection{Discrete Regimes}

Once the long-run relation is established, the following discrete regime-switching panel error-correction model is estimated

$$
\Delta y_{i, t}=\epsilon_{i, t}+\left\{\begin{array}{l}
\theta_{1}+\gamma_{1} E C_{i, t-1}+\boldsymbol{\eta}_{1}^{\prime} \Delta \mathbf{x}_{i, t-1} \text { if } \omega_{i, t} \geq \tau \\
\theta_{2}+\gamma_{2} E C_{i, t-1}+\boldsymbol{\eta}_{2}^{\prime} \Delta \mathbf{x}_{i, t-1} \text { if } \omega_{i, t}<\tau
\end{array}\right.
$$

where $E C_{i, t-1}$ is the real exchange rate misalignment from equilibrium as implied by equation (1) and $\omega_{i, t}$ is the threshold variable. We consider three regime variables along which nonlinearities can arise: the level of gross public debt as a share of GDP, the level of gross external debt liabilities as a share of GDP, and the level of net external liabilities as a share of GDP. The empirical specification is flexible in that it allows all regressors to have a regime-dependent coefficient. While it is plausible to assume that the real exchange rate should not experience trend growth over prolonged periods of time, it is quite restrictive to impose a regime-dependent intercept of zero. Thus, the regime-dependent constant captures sustained appreciation or depreciation of the real exchange rate. Furthermore, since fixed effects are a part of the cointegrating vector and appear as a component of the error-correction term $E C_{i, t-1}$, equation (2) is estimated in pooled form.

Alternatively, equation (2) can be rewritten as

$$
\Delta y_{i, t}=\mathbf{\Theta}_{1}^{\prime} \mathbf{X}_{i, t-1} I\left[\omega_{i, t} \geq \tau\right]+\mathbf{\Theta}_{2}^{\prime} \mathbf{X}_{i, t-1} I\left[\omega_{i, t}<\tau\right]+\epsilon_{i, t}
$$

where $\boldsymbol{\Theta}_{i}^{\prime}=\left[\theta_{i}, \gamma_{i}, \boldsymbol{\eta}_{i}^{\prime}\right], \mathbf{X}_{i, t-1}^{\prime}=\left[1, E C_{i, t-1}, \Delta \mathbf{x}_{i, t-1}^{\prime}\right]$ and $I[\cdot]$ is an indicator function. For a given threshold value the model is linear in parameters. Thus, $\hat{\mathbf{\Theta}}_{i}^{\prime}$ can be estimated using pooled OLS, while the threshold level $\tau$ is obtained by minimizing the residual variance $\hat{\tau}=\arg \min _{\tau} \hat{\sigma}^{2}(\tau)$.

\footnotetext{
${ }^{9}$ One potential explanation for the non-robust slope estimate on net external assets is that most of the variation in this variable emanates from the cross-sectional dimension, therefore making it difficult to detect a clear-cut association with the real exchange rate in fixed effects estimation. See Chinn and Prasad (2003).

${ }^{10}$ For applications of this approach see Galstyan and Lane (2009) and Galstyan (2015).

${ }^{11}$ See Chen and Rogoff (2003) or Cashin et al. (2004) for instance.
} 


\subsubsection{Continuous Regimes}

We note that equation (2) has explicit links to smooth transition models. In particular, the single threshold panel model is nested by our second specification, the logistic panel smooth transition error-correction model

$$
\Delta y_{i, t}=\theta+\gamma E C_{i, t-1}+\boldsymbol{\eta}^{\prime} \Delta \mathbf{x}_{i, t-1}+\left(\theta^{*}+\gamma^{*} E C_{i, t-1}+\boldsymbol{\eta}^{* \prime} \Delta \mathbf{x}_{i, t-1}\right) G\left(\omega_{i, t} ; \varphi, \tau\right)+\epsilon_{i, t}
$$

where $G\left(\omega_{i, t} ; \varphi, \tau\right)=\left[1+\exp \left(-\varphi\left(\omega_{i, t}-\tau\right)\right)\right]^{-1}$. For the purposes of discussion, we denote the coefficients in the linear and non-linear components of equation (4) by the vectors $\boldsymbol{\Gamma}$ and $\boldsymbol{\Gamma}^{*}$. Taking a closer look, $G(.) \in[0,1]$ is a continuous transition function of the logistic variety that governs the non-linear (short-run) behavior of the real exchange rate. The slope or smoothness parameter $\varphi>0$ determines the speed of transition between the extreme regimes at $G()=$.0 and $G()=$.1 respectively, with higher values of $\varphi$ indicating faster transition. The model implies that the two extreme lower and upper regimes are associated with low and high values of $\omega_{i, t}$, with a single monotonic transition of coefficients from $\boldsymbol{\Gamma}$ to $\boldsymbol{\Gamma}+\boldsymbol{\Gamma}^{*}$ as $\omega_{i, t}$ rises where the change is centered around $\tau$. As evident in this case, the dynamics of the real exchange rate are effectively a weighted average of the dynamics of the respective extreme regimes. In other words, an observation has effective regression coefficients $\Gamma+\Gamma^{*} G($.$) and is assigned to the low (high)$ regime when $G()<.(>) 0.50$. An alternative view of equation (4) is that it allows for a "continuum" of regimes, each corresponding to a different value of $G(.) \in[0,1]$. Our analysis naturally adopts the former interpretation.

As $\varphi \rightarrow \infty$, the logisitic function $G\left(\right.$.) approaches the indicator function $I\left[\omega_{i, t}>\tau\right]$ and consequently the change in $G\left(\right.$.) from 0 to 1 becomes instantaneous at $\omega_{i, t}=\tau$. In this limiting case, equation (4) reduces to the dynamic panel threshold model we initially estimate. Conversely, as $\varphi \rightarrow 0, G($.) tends to a constant and the smooth transition model dwindles down to a homogeneous or linear dynamic panel regression model.

An application of the non-linear least squares (NLS) procedure retrieves estimates of the parameters in equation (4). Under the additional assumption that the errors $\epsilon_{i, t}$ are normally distributed, NLS is equivalent to maximum likelihood. Otherwise, the NLS estimates can be interpreted as quasi-maximum likelihood estimates. 


\section{Data}

Our analysis is conducted for a balanced panel of 10 emerging market economies, as listed in Appendix B, over the period 1990-2011. All data employed are annual. We note that the data at our disposal are restricted by availability and quality. For instance, we observe a much lower incidence of dual or multiple exchange rate episodes post 1990 across emerging markets which could potentially obscure estimation results. ${ }^{12}$ Adopting a panel framework helps to avoid degrees of freedom issues and may also be regarded as more parsimonious given the relative homogeneity of the countries at hand.

The real effective exchange rate is constructed using consumer price indexes and period-average nominal exchange rates obtained from the International Monetary Fund's World Economic Outlook and International Financial Statistics databases respectively, with trade weights provided by Bayoumi et al. (2005). ${ }^{13}$ The trade balance on goods and services as a share of GDP is taken from the World Bank's World Development Indicators database. GDP per capita in constant national prices, government consumption expenditure as a share of GDP, and government gross debt as a share of GDP are available from the International Monetary Fund's World Economic Outlook database. Finally, gross external debt liabilities and net external liabilities as shares of GDP are acquired from the updated External Wealth of Nations II dataset of Lane and Milesi-Ferretti (2007). Missing observations are supplemented with data from national and other international sources.

Since the explanatory variable is the multilateral real exchange rate vis-à-vis major trading partners, it is important to measure all country level regressors in relative terms. ${ }^{14}$ To construct trade-weighted relative variables, the overall 26 most important trading partners of the 10 emerging markets considered are used. ${ }^{15}$

\section{Preliminary Results}

Before turning to the full sample panel estimates of the cointegrating regression and error-correction models, we provide some preliminary evidence on the speed of real exchange rate adjustment. Fundamentally, our concern lies in determining whether signif-

\footnotetext{
${ }^{12}$ China, being a major trading partner for many of the emerging markets, up until the early 1990 s operated two exchange rates.

${ }^{13}$ The real effective exchange rate is calculated as a weighted geometric average of consumer prices in the home country relative to that of its trading partners, expressed in common currency terms.

${ }^{14}$ Galstyan (2015) has shown that the relative trade balance is the correct variable to include on the right hand side.

${ }^{15}$ The average trade weight vis-à-vis the 26 trading partners across our primary sample of emerging economies is approximately 85 percent. The total trade weight for each of the 10 primary sample countries is at least 80 percent. The list of trading partners is also provided in appendix B.
} 
icant debt-contingent asymmetries exist in the rate of real exchange rate convergence. To this end, in a first attempt, we use the median level of debt to split the full sample into low and high debt groups of observations respectively and subsequently execute the linear variant of equation (2), in which the misalignment term is now measured as the deviation from a Hodrick-Prescott trend, for each of the sub-samples. ${ }^{16}$ The upper panel of Figure 1 ((a)-(c)) depicts the relevant results where values on the $\mathrm{x}$-axis correspond to sub-group debt averages. In the case of the public debt variable, the graph shows that the point estimate of the adjustment coefficient on the misalignment term is marginally larger in absolute value when considering the high debt sub-sample. One standard error bands, however, suggest regime independence. In the case of the gross external debt liabilities and net external liabilities, the graphs show that the adjustment coefficients on the misalignment term in absolute value are much larger in the high debt sub-sample. Thus, the estimates suggest that real exchange rate persistence is notably higher at lower levels of debt. ${ }^{17}$ We ultimately interpret these findings as initial support for the notion of debt-dependent asymmetric real exchange rate adjustment dynamics.

To be more certain of the existence of such nonlinearities, we subsequently adopt a more rigorous approach as an alternative and a precursor to the formal regime-switching analysis that follows in section 5. In this instance, the strategy first entails dividing the full set of observations into four sub-samples in accordance with the quartiles of debt, such that we have ascending levels of debt from the first to the last group. Afterwards, the linear equivalent of the error-correction model in equation (2) is estimated for each of the four sub-groups, with the misalignment term this time defined as the deviation from the exchange rate equilibrium implied by the long-run cointegrating relation in equation (1). ${ }^{18}$ The lower panel of Figure 1 ((d)-(f)) plots the estimated error-correction coefficients, alongside their respective confidence intervals of plus or minus one standard deviation, against the sub-sample debt averages. The charts overwhelmingly point to nonlinear short-run exchange rate dynamics that typically feature faster rates of equilibriumreversion at larger values of the threshold variable. As can be seen from the figure for the first debt measure, the adjustment coefficient is indifferent from zero in the lowest quartile characterized by an average public debt level of approximately 20 percent of GDP, whereas it hovers around -0.10 in the highest quartile characterized by an average debt level of about 70 percent of GDP. Importantly, the largest absolute value of the mean

\footnotetext{
${ }^{16}$ The low (high) debt group of observations is characterized by debt levels below (above) the median debt level of the entire sample.

${ }^{17}$ Alternatively, the conditional probability of mean reversion is higher in the high-debt state.

${ }^{18}$ Real exchange rate misalignments are defined as percentage deviations from the fundamentals-based equilibrium real exchange rate, such that positive gaps indicate overvaluation and negative gaps indicate undervaluation.
} 
reversion coefficient is about 0.40 and occurs at debt levels in the neighborhood of 46 percent of GDP, a level previously related to debt substantiality. In the case of gross external debt liabilities, the corresponding numbers are -0.10 and -0.40 . In contrast, these figures are quite similar for net external debt with second and third quartiles exhibiting much faster adjustment.

\section{Panel Results}

\subsection{Cross-Sectional Dependence}

Table 1 presents the results of the cross-sectional dependence (CSD) test of Pesaran (2004), and the Breusch-Pagan LM (BP-LM) test for heterogeneous residuals across panels for each of the relevant variables. The first and second columns in Table 1 show the average and average absolute values respectively of the cross-sectional correlation coefficients (off-diagonal elements) obtained from the Pesaran CSD test. Meanwhile, the third column reports the CSD test statistics.

As evident, although mostly statistically significant, the correlations over the different variables are relatively low which justifies our approach based on cross-sectional independence. ${ }^{19}$ The latter implies that overall global shocks, or common components across panels, may not be greatly important in our study. At the same time, it is nevertheless interesting to note that the real exchange rate and GDP per capita have the highest and most significant correlations of all the macroeconomic indicators, perhaps suggesting a certain degree of synchronization in economic cycles across countries. To a lesser extent, the correlations for trade balances and some of the debt and fiscal indicators may also imply this. These could, for example, be emanating from the relatively homogeneous experiences of the Asian economies in our sample during the 1996/97 crisis. Indeed, the ultimate deep recessions and large real exchange rate depreciations at the time were a pervasive feature across this region. With respect to trade balances, much of Asia observed upward trending net exports (surpluses) from the late 1990s onwards with similar patterns developing in the early 2000s for some of the Latin American economies. The final column of Table 1 displays the BP-LM test results. In all cases but one, the null is convincingly rejected at conventional statistical significance levels, thus suggesting that residual variances across panels are heterogeneous. Therefore, a heterogeneous covariance matrix of residuals is used.

\footnotetext{
${ }^{19}$ In finite samples Pesaran (2004) suggests using the assumption of cross-sectional independence when the cross-sectional correlation is low.
} 


\subsection{On Stationarity}

Table 2 reports the p-values of a range of panel unit root tests across the different variables of concern. In the case of the Pesaran (2007) with cross-sectional dependence (PCSD), Breitung (BTNG), Im-Pesaran-Shin (IPS) and Phillips-Perron Fisher (PP-F) panel unit root tests, the null hypothesis is that all series are non-stationary. Conversely, the null hypothesis for the Hadri Lagrange multiplier (HADRI) test is that all series are stationary. Overall, the PP-F and HADRI tests provide the most support for the presence of random walk dynamics across all variables. Specifically, one fails to reject the relevant null in all cases at the 5 percent level using the former test, and succeeds in rejecting the applicable null in all cases at the 1 percent level using the latter test.

Focusing on the public debt and terms of trade variables, all tests yield evidence in favor of non-stationarity at conventional significance levels. For all other variables, the results are somewhat mixed. Assessing the p-values for the real exchange rate, we observe that the BTNG, IPS and PP-F tests reject the null of non-stationary panels. However, once we account for any potential cross-sectional dependence across panels (PCSD test), the opposite conclusion is reached. Moreover, the HADRI test also implies that the exchange rate is characterized by unit root behavior. Moving on to the trade balance and government expenditure, evidence in support of unit root panels cannot be obtained with the PCSD, BTNG and IPS tests, while the converse is true with the PP-F and HADRI tests. For these two variables, we found the first-order autoregressive coefficients in both fixed effects and pooled panel specifications to be quite high at around 0.80 to 0.90 . In addition, the majority of country-level unit root tests strongly point toward non-stationarity. Lastly, in the case of GDP per capita, the BTNG, IPS and HADRI tests indicate non-stationarity at conventional significance levels while the PP-F test fails to

reject the null at the 5 percent level. In contrast, as signaled by the very low p-value, the PCSD test delivers strong evidence against the random walk hypothesis. On the basis of the overall findings, it is therefore pragmatic to treat our covariates as non-stationary variables.

Given these results, we proceed to examining whether the aforementioned variables share a common stochastic trend via panel cointegration methods. If feasible, such an approach yields equilibrium exchange rates which serve as a useful benchmark for subsequent analysis of short-run dynamics. 


\subsection{Cointegration and the Fundamentals-Based Equilibrium}

Table 3 presents the results of the cointegration test proposed by Kao and Chiang (2000) for four different combinations of variables considered. ${ }^{20}$ The null of no cointegration is rejected at the 5 percent level in specifications with the public debt variable. We next explicitly estimate the long-run equilibrium relation for these combinations. Panel A of Table 4 presents the corresponding coefficient estimates. Across all specifications the regressor slopes are predominantly of the anticipated signs. Given statistical insignificance of the terms of trade variable we choose column (1) as our benchmark specification.

Concentrating on the benchmark, we note that all estimates are statistically significant. The coefficient on the trade balance is negative and implies that a 1 percentage point rise in the relative trade balance is associated with approximately a 1.74 percent real exchange rate depreciation in equilibrium. The estimate on GDP per capita is negative and insignificant at the 5 percent level. ${ }^{21}$ One potential reason for the finding is that relative GDP per capita might not be a sufficiently accurate proxy for relative productivity differentials. Lastly, the sign on coefficients of government spending and debt variables is consistent with our theory. In particular, a 5 percent increase in relative public spending is associated with a 1 percent appreciation of the real exchange rate, while a 10 percent increase in relative public debt is associated with a 1.10 percent decline in the real exchange rate.

\subsection{Error Correction and the Role of Debt}

\subsubsection{Baseline Linear Model}

Panel B of Table 4 first presents the linear error-correction model estimates in order to give us a general impression of the overall degree of exchange rate persistence across emerging markets in the sample. The table shows that the short-run dynamics of the real exchange rate are influenced by deviations from the estimated benchmark relation. The error-correction coefficients imply that these misalignments diminish very slowly,

\footnotetext{
${ }^{20}$ We are restricted in our choice of alternative tests and estimations. For instance, we postulate that the error-correction term is regime-dependent, while both Johansen (1991) and Westerlund (2007) are tests that rely on a regime-independent form of error correction.

${ }^{21}$ The cointegrating vector estimated by weighted FMOLS is not invariant to the ordering of regressors. We have considered all twenty four permutations of the right hand side variables in our preferred specification in column 1. We found that relative GDP per capita is statistically insignificant in sixteen cases, while the variation in magnitudes is negligible to have an impact on the findings presented in the rest of our tables. For sensitivity we have also considered standard FMOLS where the results are invariant to the ordering of variables. We found that per capita GDP is insignificant at all conventional levels.
} 
with a half-life of roughly 4 years assuming a monotonic rate of decay. ${ }^{22}$ In addition, the constant, reflecting sustained movements of the real exchange rate, is found to be insignificantly different from zero.

\subsubsection{Discrete-Regime Nonlinear Model}

In this section, we relax the assumption of a single regime and turn to the discrete regimeswitching error-correction model as represented by equation (2). The central estimates of the single threshold panel regression are displayed in Table 5. The regime variable in column (1) is gross public debt, in column (2) it is gross external debt, while in column (3) it is net external liabilities. For each type of debt the start of period values are considered when estimating the model. The threshold and regime-specific coefficients are determined simultaneously.

Figure 2 plots the inverse log-likelihood ratio for each of the estimated threshold parameters. The graphs indicate that the estimated thresholds of 51 percent of GDP for public debt, 56 percent of GDP for external debt liabilities, and 34 percent of GDP for net foreign liabilities in columns (1), (2) and (3) of Table 5 are statistically significant. Furthermore, the confidence intervals for these estimates are reasonably small as shown by the charts. We note that the reported threshold parameters are quite consistent with the low debt default thresholds empirically observed in emerging market economies. Importantly, these countries have typically experienced significant real exchange rate movements in the neighborhood of such debt levels. ${ }^{23}$

Inspecting rows (5) and (6) in Table 5, one ascertains that most of the differences between regime-specific coefficients are statistically significant according to the Wald test of coefficient equality. Moreover, the majority of these discrepancies are quite pronounced quantitatively. Evidently, the most salient feature of the table is the realization of much faster real exchange rate adjustment in the "high-debt" regime, characterized by debt levels equal to or above the debt threshold. ${ }^{24}$ To provide a sense of the estimates, we again consider the half-life of deviations from equilibrium. Based on the coefficient val-

\footnotetext{
${ }^{22}$ This real exchange rate half-life is consistent with those typically reported in the literature.

${ }^{23}$ See Reinhart and Rogoff (2009) for an excellent review of emerging market debt defaults.

${ }^{24} \mathrm{We}$ also analyze the relation between the change in the logarithm of the real exchange rate and the lagged error-correction term derived from the panel cointegrating regression on an individual country basis. Our country-specific analysis offers some support for the notion that emerging markets with high debt levels exhibit more volatile real exchange rate changes, larger error-correction terms, and a more pronounced inverse gross correlation between the two aforementioned variables. Furthermore, under high debt, negative error-correction terms are more frequently linked to positive exchange rate changes while positive error-correction terms are more regularly associated with negative exchange rate growth. These features tend to suggest that emerging markets characterized by high debt levels generally display more volatile exchange rates with less persistent misalignments.
} 
ues, the calculated half-lives are found to be around 1.30, 1.60 and 2.70 years (public debt, external debt liabilities, and net external liabilities correspondingly) in the "high-debt" regime, which are much smaller than the half-lives observed in the "low-debt" regime characterized by debt levels below the debt threshold. In fact, real exchange rate dynamics in the "low-debt" regime exhibit random walk type behavior given the statistical insignificance of the error-correction coefficients. Disregarding statistical insignificance in this regime, the highly persistent dynamics could still be approximated by a unit root process. $^{25}$

Regarding the regime-specific constant term, columns (1)-(3) of Table 5 resoundingly report that sustained movement of the real exchange rate is effectively zero in the "lowdebt" regime, while signaling that significant sustained depreciation to the tune of 4 percent per annum typically arises in the "high-debt" regime. ${ }^{26}$ Finally, note that the estimated residual variance corresponding to public debt is slightly lower than the residual variances in the cases of gross external debt and net foreign liabilities. Thus, in the case of the error-correction model also, statistical preference is marginally tilted toward the specification featuring public debt.

\subsubsection{Continuous-Regime Nonlinear Model}

Turning attention to the dynamic panel smooth transition error-correction model estimates of Table 6 , we observe that overall results tend to be qualitatively similar. ${ }^{27} \mathrm{We}$ note once again that high (low) values of the debt transition variable $\omega_{i, t}$ are associated with the upper (lower) regime of real exchange rate dynamics in which the relevant regressor coefficients are approximately $\Gamma+\Gamma^{*}(\Gamma)$, representing the sum of the linear and nonlinear components' coefficients (linear coefficient) as the transition function tends to one (zero). To focus discussion and facilitate interpretation, we concentrate

\footnotetext{
${ }^{25}$ In the case of a unit root the half-life is infinite. However, it can also be finite but uninformative. See Evans (2013).

${ }^{26}$ Column (3) with net foreign liabilities is the only exception to the latter.

${ }^{27}$ In line with Teräsvirta (1994), we conducted tests of linearity against smooth transition type nonlinearities in the univariate (self-exciting threshold) case across different debt samples prior to estimating equation 4. The test entails taking a third-order Taylor expansion of the logistic transition function and ultimately estimating the auxiliary regression $y_{i, t}=\beta_{00}+\sum_{j=1}^{p}\left(\beta_{0 j} y_{i, t-j}+\beta_{1 j} y_{i, t-j} y_{i, t-d}+\beta_{2 j} y_{i, t-j} y_{i, t-d}^{2}+\right.$ $\left.\beta_{3 j} y_{i, t-j} y_{i, t-d}^{3}\right)+\eta_{i, t}$ where $p=1$ and $d=1$ is the delay parameter. The null hypothesis of linearity $H_{0}: \beta_{11}=\beta_{21}=\beta_{31}=0$ is then tested against the general alternative that $H_{0}$ is invalid. Moreover, if one is able to reject $\beta_{3 j}=0$, the smooth transition model is of the logistic variety. For the full sample, we were able to convincingly reject the aforementioned restrictions. However, once we divided our sample by median debt levels and applied the test to each of the resulting (approximately equally sized) sub-samples, we often failed to reject the proposed restrictions or obtained weaker evidence against the null. This suggested the existence of debt-contingent smooth transition type asymmetries.
} 
on the regression coefficients corresponding to the extreme lower and upper regimes at $G\left(\omega_{i, t} ; \varphi, \tau\right)=0$ and 1 respectively.

Our estimates indicate that real exchange rate adjustment is typically faster at higher levels of debt. This result is particularly pronounced in the case where gross public debt is employed as the transition variable $\omega_{i, t}$ (column (1)). ${ }^{28}$ Importantly, support for nonlinear dynamics of the logistic smooth transition variety is relatively weak in the gross external debt liability threshold specification, as signalled by the presence of an insignificant transition parameter. It has been argued, however, that insignificance of $\varphi$ should not be taken as outright evidence against smooth transition-type nonlinearities. Specifically, it can be quite difficult to retrieve accurate estimates of the transition parameter when it is relatively large as in this instance the shape of the (logistic) transition function changes only little. Therefore, in order to obtain a precise estimate of $\varphi$ one needs many observations in the immediate local neighborhood of the threshold $\tau$. Given that this is usually not the scenario, the transition parameter often appears to be statistically insignificant even when the true population parameter indicates otherwise. Regarding the location parameters $(\tau)$, the estimates roughly match those of the discrete nonlinear error-correction model. On the other hand, unlike in the discrete regime-switching model, the constant terms in either of the extreme regimes of the gross debt threshold specifications are insignificant. Meanwhile, the situation is reversed when examining the net foreign liabilities threshold model in column (3). Ignoring standard errors, there is general evidence of more negative coefficients in the upper regime indicating more protracted depreciation.

Figure 3 plots the transition function, $G($.$) , against the transition variable, \omega_{i, t}$, for each of the specifications in Table 6 . The graphs indicate an adequate spread of observations between the low and high regimes of real exchange rate dynamics. ${ }^{29}$ Conversely, if the threshold estimate was erroneously too high or too low, there would be a marked uneven spread of observations across the two regimes and consequently the model would not be well specified. The estimate of the smoothness parameter $\varphi$ is 5.37 in the case of public debt as the threshold variable (panel (a)), 11.93 in the case of external debt liabilities as the threshold variable (panel (b)), and 1.00 in the case of net external liabilities as the threshold variable (panel (c)). As can be seen from the graphs, transition between the extreme regimes prevailing at $G()=$.0 and $G()=$.1 is fastest in the second instance where the value of $\varphi$ is largest. Conversely, it is slowest in the third instance where the transition function is relatively flat and extreme regimes are never reached within the

\footnotetext{
${ }^{28}$ Note that statistical preference is again tipped toward this specification given its marginally lower residual variance (i.e. compared to those in columns (2) and (3)).

${ }^{29}$ Note that $G()=$.0.50 when $\omega_{i, t}=\tau$
} 
sample. Thus, for high values of $\varphi$, the smooth transition model is well approximated by the discrete transition model and vice versa. Compared to the discrepancy across columns (1) or columns (3) of Tables 5 and 6 respectively, it is indeed evident that the smooth model estimates in column (2), consisting of a larger transition parameter, are overall more closely aligned with the corresponding discrete model estimates.

Finally, Figure 4 plots $G($.$) over the sample period for each country. The red and$ blue plots track the transition functions with gross public debt and gross external debt liabilities, while the green plot gives the transition function with net foreign liabilities. From the graphs, we observe that movements in the three debt measures are typically positively correlated, with total government debt liabilities vis-à-vis foreign creditors being the natural link across the three definitions. ${ }^{30}$ Moreover, it is evident that most of the emerging markets have spent considerable time, and in a number of these cases many consecutive periods, in the upper debt regime $(G() \geq 0.50$.$) . Thus, our sample of$ "high-debt" observations is not overly reliant on any single country.

\subsubsection{Consolidated Summary}

Overall, the results deliver an unequivocal message: short-run real exchange rate dynamics display significant debt-contingent asymmetries, where the "high-debt" regime normally displays a much faster closing of real exchange rate misalignments in comparison to the highly persistent, random walk type behavior of the exchange rate in the "low-debt" regime. Our findings are in line with the general experiences of emerging markets. At higher debt levels, close to around 50 to 60 percent of output on average, a sudden shock can trigger a widening of spreads, leading to an abrupt change in the speed of real exchange rate adjustment manifested in the form of significant exchange rate depreciation. ${ }^{31}$ As suggested by the linear error-correction model, ignoring the vital role of debt in exchange rate dynamics only acts to blur the lines of analysis.

\footnotetext{
${ }^{30}$ Nearly all country-specific pairwise gross correlations are positive and statistically significant at the 1 percent level. For levels of debt, the average correlations are 0.71 between gross external debt liabilities and net external liabilities, 0.42 between gross external debt liabilities and gross public debt, and 0.47 between net external liabilities and gross public debt. The corresponding figures for transition functions are 0.67, 0.41 , and 0.44 .

${ }^{31}$ Reinhart and Rogoff (2009) document that more than half of all defaults between 1970 and 2008 occurred at levels of (external) debt below 60 percent of GNP.
} 


\section{Regimes and Sources of Misalignment Variance}

In the preceding section we studied the asymmetry of exchange rate adjustments based on an endogenous classification of observations into two distinct regimes. In this section we take a look at the variability of changes in misalignments and its core components: changes in the nominal effective exchange rate and trade weighted inflation differentials. $^{32}$ Employing gross public debt as the threshold indicator, the respective standard deviations of these variables are presented in Table 7. It is interesting to note that the variability of misalignments in the "high-debt" regime is almost twice as large as that in the "low-debt" regime (0.16 and 0.09 standard deviations respectively). This observation is consistent with our finding of near random walk behavior of the real exchange rate in the "low-debt" regime where there is little tendency of reversion to the fundamental equilibrium compared with mean reversion in the "high-debt" regime.

On the other hand, the variability of the nominal effective exchange rate and trade weighted inflation-differentials is larger in the "low-debt" regime compared to the "highdebt" regime. This observation could capture more in-tune movements of these variables in the latter regime. Finally, note that the standard deviation of the nominal effective exchange rate is marginally higher than the standard deviation of the trade-weighted inflation differentials in the "low-debt" regime. The converse is true in the "high-debt" regime. This finding is not surprising given the higher estimated half-life in the "lowdebt" case.

To further explore the determinants of real exchange rate misalignment variability, we relate changes in misalignments to changes in the nominal effective exchange rate, trade-weighted inflation differentials and lagged levels of the latter variables so that past movements are fully filtered through. ${ }^{33}$ The results are presented in Table 8 with gross public debt acting again as the threshold variable. An important feature of the table is the relatively low residual sum of squares in the "high-debt" regime with R-squared values in low and high debt specifications standing at approximately 0.62 and 0.90 respectively. This suggests that most movements in the misalignment term in the upper regime are driven by changes in the nominal effective exchange rate and relative prices. In the lower regime, in contrast, movements in fundamentals are considerably more important, accounting for about a third of the changes in misalignments. Furthermore, the marginal contribution of the nominal effective exchange rate is always larger than the

\footnotetext{
${ }^{32}$ The variance of the measured misalignment is larger than the variance of the true gap since the equilibrium level of the real exchange rate is not observed.

${ }^{33}$ Note that measurement errors in the misalignment term will tend to reduce the precision of OLS parameter estimates.
} 
contribution of the inflation differential, as reflected by the higher marginal R-squared terms.

With respect to coefficients, we note that the estimate on the nominal effective exchange rate is always larger in the "high-debt" regime. In particular, the coefficient is found to be less than one which may indicate that movements in the nominal effective exchange rate affect fundamentals and correspondingly the equilibrium exchange rate. The coefficient on the inflation differential is also smaller in the lower regime and is similar in magnitude to that of the nominal effective exchange rate. In the upper debt regime however, the coefficient is much larger and indifferent from one. This latter result coincides with the profound high-inflation experiences of emerging markets during the relevant sample periods. From a theoretical standpoint, employing a DSGE model Faraglia et al. (2012) show that higher levels of government debt can lead to higher inflation with longer maturity debt leading to more persistent inflation. This may help explain the larger coefficient on the inflation differential in the upper regime (i.e. larger effects at relatively higher inflation rates).

In relation to lagged differences, we observe that they too enter significantly. Although their marginal contribution is relatively low, the negative coefficients imply some retrenchment of the gap after the initial move. Lastly, the lagged misalignment term is positive and statistically significant in the upper regime while insignificant in the lower regime, indicating the presence of inertia in changes of the misalignment in a "high-debt" environment. Overall, these results confirm the existence of differences in the underlying mechanics of exchange rate adjustment and sources of misalignment volatility across debt regimes in emerging markets.

\section{Conclusions}

This paper studies the existence of short-run debt-contingent asymmetries in real exchange rate dynamics for a group of emerging market economies. We find that the exchange rate is significantly more persistent during times of low debt (either public or external). Thus, we ascertain that a directional move towards the fundamental equilibrium is more likely when debt levels are high. By decomposing the real exchange rate and examining the underlying sources of fluctuations of misalignments, we find further evidence of debt contingency. We find that real exchange rate misalignments tend to be more volatile during periods of high debt, with trade-weighted nominal exchange rates and inflation differentials capturing a more significant proportion of misalignments than in states of low debt during which fundamentals exert a greater effect. 
Overall, our results are consistent with the actual experiences of emerging markets. Fundamentally, they suggest that future research on real exchange rate movements in the non-industrialized world must adequately account for the role of debt in the adjustment process. Finally, our findings should prove to be useful to both theoretical economists and policy-makers dealing with issues pertaining to the speed and smoothness of external adjustment.

\section{Acknowledgements}

We thank Philip Lane, the editor and the referees for helpful comments. 


\section{References}

Adam, Christopher and David Bevan (2005), "Fiscal Deficits and Growth in Developing Countries," Journal of Public Economics 89, 571-597.

Bayoumi, Tamim, Jaewoo Lee and Sarma Jayanthi (2005), "New Rates from New Weights," IMF Working Paper No. 05/99.

Breitung, Jörg and Hashem Pesaran (2008), "Unit Roots and Cointegration in Panels," in L. Mátyás and P. Sevestre (Ed), The Econometrics of Panel Data, Springer.

Cashin, Paul, Luis Céspedes and Ratna Sahay (2004), “Commodity Currencies and the Real Exchange Rate," Journal of Development Economics 75, 239-268.

Catão, Luis and Gian Maria Milesi-Ferretti (2014), “External Liabilities and Crises," Journal of International Economics 94, 18-32.

Chen, Yu-Chin and Kenneth Rogoff (2003), “Commodity Currencies," Journal of International Economics 60, 133-160.

Chinn, Menzie and Eswar Prasad (2003), "Medium-Term Determinants of Current Accounts in Industrial and Developing Countries: An Empirical Exploration," Journal of International Economics 59, 47-76.

Chinn, Menzie (2012), "Macro Approaches to Foreign Exchange Determination," in J. James et al (Ed), Handbook of Exchange Rates, Wiley.

Cohen, Daniel (1993), “Low Investment and Large LDC Debt in the 1980s," American Economic Review 83, 437-449.

Evans, Martin (2011), Exchange-Rate Dynamics, Princeton, NJ: Princeton University Press.

Faraglia, Elisa, Albert Marcet, Rigas Oikonomou and Andrew Scott (2013), "The Impact of Debt Levels and Debt Maturity on Inflation," Economic Journal 123, 164-192.

Galstyan, Vahagn and Philip Lane (2009), "The Composition of Government Spending and the Real Exchange Rate," Journal of Money, Credit and Banking 41, 1233-1249.

Galstyan, Vahagn (2015), “Country Size and Exchange Rates," Economica 82, 222-235.

Galstyan, Vahagn and Adnan Velic (2016), “Taxation, Debt and Relative Prices in the Long Run: The Irish Experience," mimeo. 
González, Andrés, Timo Teräsvirta, Dick van Dijk (2005), "Panel Smooth Transition Regression Models," SSE/EFI Working Paper Series in Economics and Finance, Research Paper No. 604.

Gourinchas, Pierre-Olivier and Maurice Obstfeld (2012), "Stories of the Twentieth Century for the Twenty-First," American Economic Journal: Macroeconomics 4, 226-265.

Hansen, Bruce (1999), “Threshold effects in non-dynamic panels: Estimation, testing and inference," Journal of Econometrics 93, 345-368.

Johansen, Søren (1991), "Estimation and Hypothesis Testing of Cointegration Vectors in Gaussian Vector Autoregressive Models," Econometrica 59, 1551-1580.

Jorda, Oscar, Moritz Schularik and Alan Taylor (2011), "Financial Crises, Credit Booms, and External Imbalances: 140 Years of Lessons," IMF Economic Review 59, 340-378.

Kao, Chihwa, and Min-Hsien Chiang (2000), "On the Estimation and Inference of a Cointegrated Regression in Panel Data," in B. H. Baltagi (Ed.), Advances in Econometrics, vol. 15, JAI Press.

Krugman, Paul (1988), "Financing vs. Forgiving a Debt Overhang," Journal of Development Economics 29, 253-268.

Lane, Philip and Gian Maria Milesi-Ferretti (2007), "The External Wealth of Nations Mark II: Revised and Extended Estimates of Foreign Assets and Liabilities, 19702004," Journal of International Economics 73, 223-250.

Michael, Panos, Robert Nobay and David Peel (1997), "Transactions Costs and Nonlinear Adjustment in Real Exchange Rates: An Empirical Investigation," Journal of Political Economy 105, 862-879.

Obstfeld, Maurice and Kenneth Rogoff (1996), Foundations of International Macroeconomics, Cambridge, MA: MIT Press.

Pattillo, Catherine, Hélene Poirson and Luca Ricci (2011), "External Debt and Growth," Review of Economics and Institutions 2, 1-30.

Pedroni, Peter (2000), “Fully Modified OLS for Heterogenous Cointegrated Panels," in B. H. Baltagi (Ed.), Advances in Econometrics, vol. 15, JAI Press.

Pedroni, Peter (2001), "Purchasing Power Parity Tests in Cointegrated Panels," Review of Economics and Statistics 83, 727-731. 
Pesaran, Hashem (1997), "The Role of Economic Theory in Modelling the Long Run," Economic Journal 107, 178-191.

Pesaran, Hashem (2004), "General Diagnostic Tests for Cross Section Dependence in Panels," CESifo Working Papers, No. 1229.

Pesaran, Hashem (2007), "A Simple Panel Unit Root Test in the Presence of CrossSection Dependence," Journal of Applied Econometrics 22, 265-312.

Reinhart, Carmen and Kenneth Rogoff (2009), This Time Is Different: Eight Centuries of Financial Folly, Princeton and Oxford: Princeton University Press.

Ricci, Luca, Gian Maria Milese-Ferretti and Jaewoo Lee (2013), "Real Exchange Rates and Fundamentals: A Cross-Country Perspective," Journal of Money, Credit and Banking 45, 845-865.

Taylor, Mark, David Peel and Lucio Sarno (2001), "Nonlinear Mean-Reversion in Real Exchange Rates: Toward a Solution to the Purchasing Power Parity Puzzles," International Economic Review 42, 1015-1042.

Teräsvirta, Timo (1994), "Specification, Estimation, and Evaluation of Smooth Transition Autoregressive Models," Journal of the American Statistical Association 89, 208-218.

Westerlund, Joakim (2007), "Testing for Error Correction in Panel Data," Oxford Bulletin of Economics and Statistics 69, 709-748. 
Figure 1: Mean-Reversion Coefficients

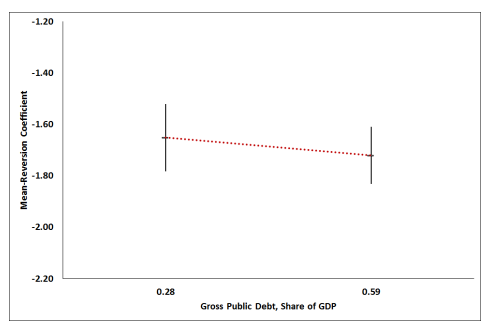

(a) Gross Public Debt

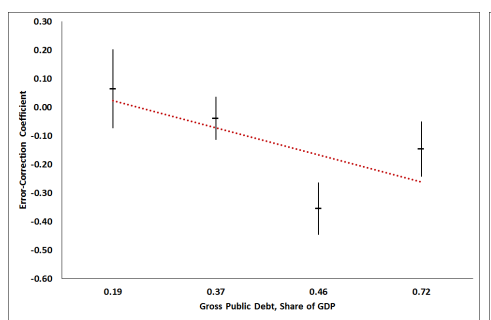

(d) Gross Public Debt

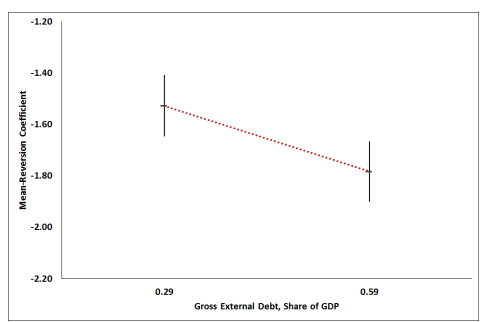

(b) Gross External Debt

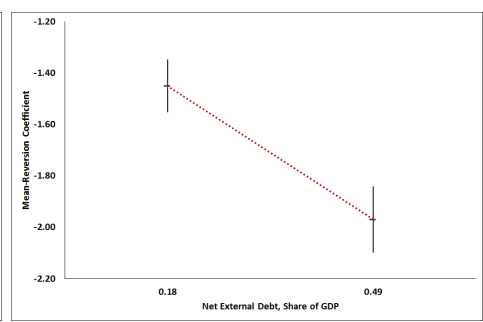

(c) Net External Liabilities

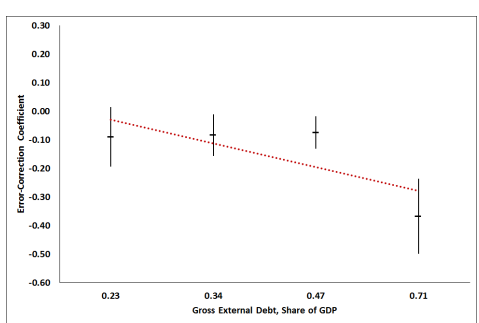

(e) Gross External Debt

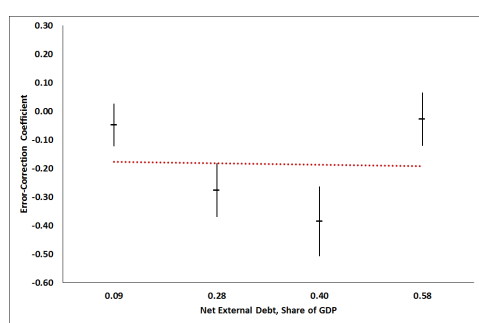

(f) Net External Liabilities

Note: Sub-figures (a)-(c) plot the adjustment coefficients with one standard error band on the deviation of real exchange rate from the Hodrick-Prescott trend for high and low debt regimes. The median level of debt is used to split the full sample into these groups of observations respectively. Sub-figures (d)-(f) plot the error-correction coefficients with one standard error band on the deviation of real exchange rate from the fundamental equilibrium for four sub-samples in accordance with the quartiles of debt. 
Figure 2: Inverse Log-Likelihood Ratio, Panel

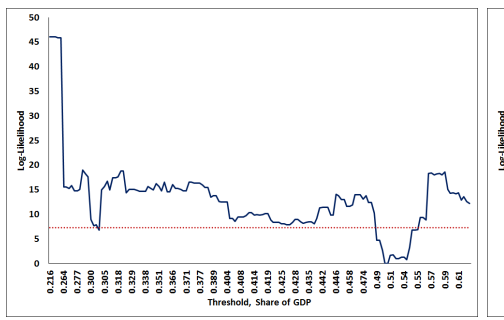

(a) Gross Public Debt

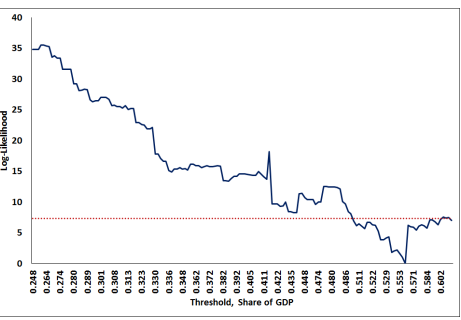

(b) Gross External Debt

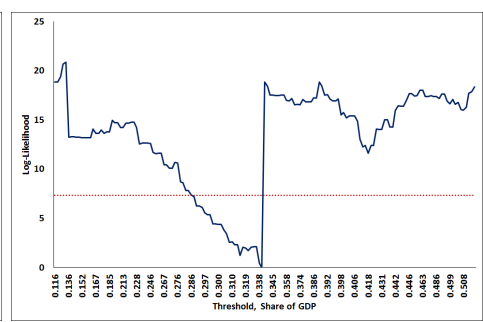

(c) Net External Liabilities

Note: The figure plots the inverse log-likelihood ratio for each of the estimated threshold parameters. Ratio below dotted line indicates statistical significance of the threshold variable. 
Figure 3: Transition Function, Panel

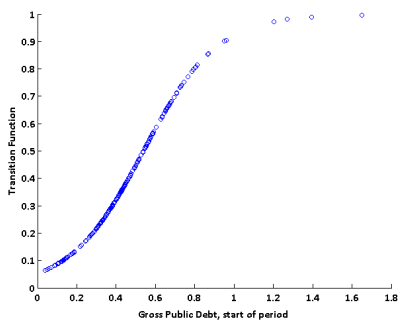

(a) Gross Public Debt

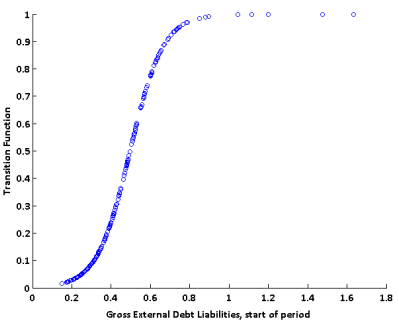

(b) Gross External Debt

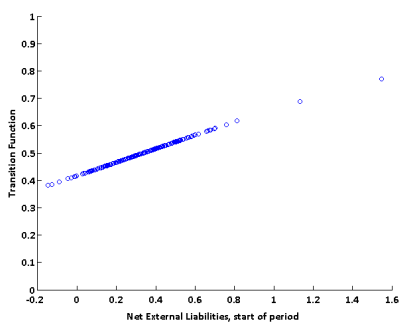

(c) Net External Liabilities

Note: The figure plots the transition function $G(.) \in[0,1]$ of the logistic panel smooth transition error-correction model in equation (2) against the respective start of period debt (as a share of GDP) threshold variables. The estimate of the smoothness parameter $\varphi$ is 5.37 in the case of gross public debt as the threshold variable (panel (a)), 11.93 in the case of gross external debt liabilities as the threshold variable (panel (b)), and 1.00 in the case of net external liabilities as the threshold variable (panel (c)). These estimates are also shown in Table 6. For larger values of $\varphi$, transition between the extreme regimes at $G()=$.0 and $G()=$.1 becomes faster (i.e. transition function becomes steeper around threshold point). Note that $G()=$.0.50 at the threshold estimate. 
Figure 4: Transition Function, Country Specific

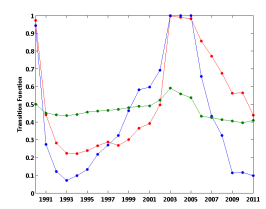

(a) Argentina

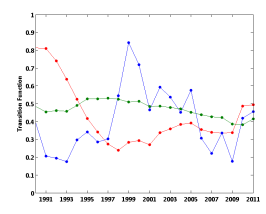

(f) Malaysia

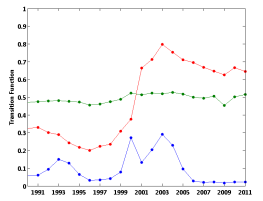

(b) Brazil

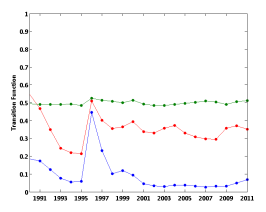

(g) Mexico

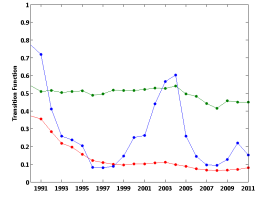

(c) Chile

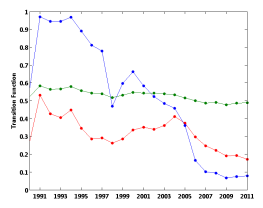

(h) Peru

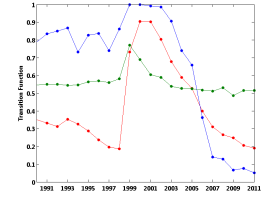

(d) Indonesia

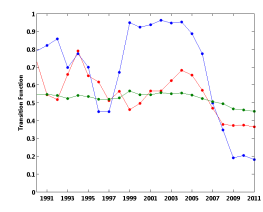

(i) Philippines

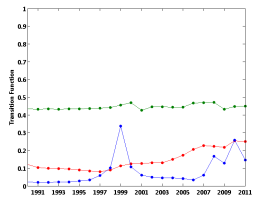

(e) Korea

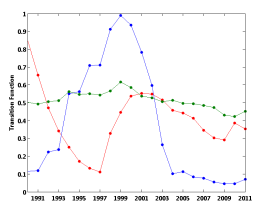

(j) Thailand

Note: The figure plots the transition function $G(.) \in[0,1]$ of the logistic panel smooth transition error-correction model in equation (2) against time for each of the countries in our sample. The red, blue, and green plots represent the transition function with gross public debt, gross external debt liabilities, and net external liabilities respectively as the threshold variable. 
Table 1: Cross-Sectional Dependence

\begin{tabular}{lllll}
\hline \hline & Rho & Rho & CSD & BP - LM \\
\hline REER & 0.18 & 0.28 & $(5.48)^{* * *}$ & $(136.9)^{* * *}$ \\
Trade Balance & 0.08 & 0.23 & $(2.51)^{* *}$ & $(93.38)^{* * *}$ \\
GDP per Capita & 0.24 & 0.35 & $(7.19)^{* * *}$ & $(178.5)^{* * *}$ \\
Public Expenditures & 0.04 & 0.20 & $(1.34)$ & $(61.11)^{*}$ \\
Public Debt & 0.05 & 0.16 & $(1.45)$ & $(47.07)$ \\
Terms of Trade & 0.06 & 0.25 & $(1.68)^{*}$ & $(111.4)^{* * *}$ \\
& & & & \\
\hline
\end{tabular}

Notes: The table presents the results of the cross-sectional dependence (CSD) test of Pesaran (2004), and the Breusch-Pagan LM (BP-LM) test for heterogeneous residuals across panels for each of the relevant variables. The first and second columns in Table 1 show the average and average absolute values respectively of the cross-sectional correlation coefficients (off-diagonal elements) obtained from the Pesaran CSD test. REER indicates the logarithm of the real effective exchange rate; Trade Balance is the relative trade balance as a share of GDP; GDP per capita is the logarithm of real relative GDP per capita; Public Expenditures is the logarithm of relative government expenditures as a share of GDP; Public Debt is the logarithm of relative government debt as a share of GDP; Terms of Trade is the logarithm of export to import price index ratio. All relative variables are computed by the author using trade shares provided by Bayoumi et al (2005) using the set of countries listed in data section. 
Table 2: Panel Unit Root Tests

\begin{tabular}{lccccc}
\hline \hline & PCSD & BTNG & IPS & PP-F & HADRI \\
& & & & & \\
\hline REER & 0.395 & 0.028 & 0.023 & 0.058 & 0.000 \\
Trade Balance & 0.071 & 0.002 & 0.000 & 0.156 & 0.000 \\
GDP per Capita & 0.009 & 0.977 & 0.153 & 0.083 & 0.000 \\
Public Expenditures & 0.055 & 0.053 & 0.035 & 0.386 & 0.008 \\
Public Debt & 0.666 & 0.894 & 0.329 & 0.441 & 0.000 \\
Terms of Trade & 0.958 & 0.681 & 0.998 & 1.000 & 0.000 \\
& & & & & \\
\hline \hline
\end{tabular}

Notes: The table reports the p-values of a range of panel unit root tests. In the case of the Pesaran with cross-sectional dependence (PCSD), Breitung (BTNG), Im-Pesaran-Shin (IPS) and PhillipsPerron Fisher (PP-F) panel unit root tests, the null hypothesis is that all series are non-stationary. Conversely, the null hypothesis for the Hadri Lagrange multiplier (HADRI) test is that all series are stationary. REER indicates the logarithm of the real effective exchange rate; Trade Balance is the relative trade balance as a share of GDP; GDP per capita is the logarithm of real relative GDP per capita; Public Expenditures is the logarithm of relative government expenditures as a share of GDP; Public Debt is the logarithm of relative government debt as a share of GDP; Terms of Trade is the logarithm of export to import price index ratio. All relative variables are computed by the author using trade shares provided by Bayoumi et al (2005) using the set of countries listed in data section. 
Table 3: Cointegration Test

\begin{tabular}{lcccc}
\hline \hline & (1) & (2) & (3) & (4) \\
\hline REER & & & & \\
Trade Balance & $\checkmark$ & $\checkmark$ & $\checkmark$ & $\checkmark$ \\
GDP per Capita & $\checkmark$ & $\checkmark$ & $\checkmark$ & $\checkmark$ \\
$\begin{array}{l}\text { Public Expenditures } \\
\text { Public Debt }\end{array}$ & $\checkmark$ & $\checkmark$ & $\checkmark$ & $\checkmark$ \\
Terms of Trade & & $\checkmark$ & & $\checkmark$ \\
Kao Cointegration Test & 0.143 & 0.043 & 0.230 & 0.038 \\
\hline \hline
\end{tabular}

Notes: Real Exchange Rate indicates the logarithm of the real effective exchange rate; Trade Balance is the relative trade balance as a share of GDP; GDP per capita is the logarithm of real relative GDP per capita; Public Expenditures is the logarithm of relative government expenditures as a share of GDP; Public Debt is the logarithm of relative government debt as a share of GDP; Terms of Trade is the logarithm of export to import price index ratio. All relative variables are computed by the author using trade shares provided by Bayoumi et al (2005) using the set of countries listed in data section. 
Table 4: Panel Cointegration Regressions

\begin{tabular}{|c|c|c|}
\hline Panel A: Long-Run Relation & (1) & (2) \\
\hline Trade Balance & -1.74 & -1.76 \\
\hline GDP per Capita & $\begin{array}{l}-0.05 \\
(0.03)^{*}\end{array}$ & $\begin{array}{l}-0.07 \\
(0.03)^{* *}\end{array}$ \\
\hline Public Expenditures & $\begin{array}{l}0.20 \\
(0.02)^{* * *}\end{array}$ & $\begin{array}{l}0.21 \\
(0.03)^{* * *}\end{array}$ \\
\hline Public Debt & $\begin{array}{l}-0.11 \\
(0.03)^{* * *}\end{array}$ & $\begin{array}{l}-0.12 \\
(0.03)^{* * *}\end{array}$ \\
\hline Terms of Trade & & $\begin{array}{l}0.02 \\
(0.02)\end{array}$ \\
\hline Observations & 220 & 220 \\
\hline Panel B: Linear Error Correction & (3) & (4) \\
\hline Error-Correction & $\begin{array}{l}-0.16 \\
(0.05)^{* * *}\end{array}$ & $\begin{array}{l}-0.17 \\
(0.05)^{* * *}\end{array}$ \\
\hline Constant & $\begin{array}{l}0.002 \\
(0.01)\end{array}$ & $\begin{array}{l}0.002 \\
(0.01)\end{array}$ \\
\hline Half-Life & 3.98 & 3.83 \\
\hline
\end{tabular}

Notes: The dependent variable is the logarithm of the real effective exchange rate; Trade Balance is the relative trade balance as a share of GDP; GDP per capita is the logarithm of real relative GDP per capita; Public Expenditures is the logarithm of relative government expenditures as a share of GDP; Public Debt is the logarithm of relative government debt as a share of GDP; Terms of Trade is the logarithm of export to import price index ratio. All relative variables are computed by the author using trade shares provided by Bayoumi et al (2005) using the set of countries listed in data section. Half-Life measured in years. Long-run relation estimated by weighted fully modified panel ordinary least squares. Error-correction model estimated by pooled OLS. Asterisks ***,*** indicate significance at $1 \%, 5 \%$ and $10 \%$ levels respectively. 
Table 5: Nonlinear Error Correction: Discrete Transition Model

\begin{tabular}{llll}
\hline \hline & (1) & (2) & (3) \\
\hline Error-Correction $\left(\omega_{i t} \geq \tau\right)$ & -0.42 & -0.36 & -0.23 \\
& $(0.09)^{* * *}$ & $(0.09)^{* * *}$ & $(0.06)^{* * *}$ \\
Error-Correction $\left(\omega_{i t}<\tau\right)$ & -0.04 & -0.06 & -0.06 \\
& $(0.06)$ & $(0.05)$ & $(0.07)$ \\
Constant $\left(\omega_{i t} \geq \tau\right)$ & -0.04 & -0.04 & -0.01 \\
& $(0.02)^{* *}$ & $(0.02)^{* *}$ & $(0.01)$ \\
Constant $\left(\omega_{i t}<\tau\right)$ & -0.01 & 0.00 & -0.00 \\
& $(0.01)$ & $(0.01)$ & $(0.01)$ \\
Test $($ Error-Correction) & $(13.37)^{* * *}$ & $(9.21)^{* * *}$ & $(3.48)^{*}$ \\
Test $($ Constant) & $(2.06)$ & $(3.79)^{*}$ & $(0.11)$ \\
& & & \\
Half-Life $\left(\omega_{i t} \geq \tau\right)$ & 1.27 & 1.55 & 2.65 \\
Half-Life $\left(\omega_{i t}<\tau\right)$ & 16.98 & 11.20 & 11.20 \\
& & & \\
Estimated Threshold & 0.51 & 0.56 & 0.34 \\
Threshold Variable & GPD & GED & NEL \\
Sigma-squared & 0.0125 & 0.0129 & 0.0134 \\
R-squared & 0.23 & 0.21 & 0.17 \\
Observations & 220 & 220 & 220 \\
& & & \\
\hline \hline
\end{tabular}

Notes: The dependent variable is the change in the logarithm of the real effective exchange rate. Half-life is measured in years. GPD, GED, and NEL denote gross public debt, gross external debt liabilities, and net external liabilities respectively. Estimated by pooled OLS. GNR-based test for autoregressive errors shows no trace of serial correlation across all specifications.

Asterisks ******* indicate significance at $1 \%, 5 \%$ and $10 \%$ levels respectively. 
Table 6: Nonlinear Error Correction: Smooth Transition Model

\begin{tabular}{llll}
\hline \hline & $(\mathbf{1})$ & $\mathbf{( 2 )}$ & $\mathbf{( 3 )}$ \\
\hline Error-Correction $(\mathrm{G}()=1)$. & & & \\
& -0.58 & -0.27 & -0.35 \\
Error-Correction $(\mathrm{G}()=0)$. & $(0.23)^{* *}$ & $(0.09)^{* * *}$ & $(0.09)^{* * *}$ \\
& 0.15 & -0.06 & 0.03 \\
Error-Correction, NL & $(0.24)$ & $(0.08)$ & $(0.02)$ \\
& -0.73 & -0.21 & -0.38 \\
Constant $(\mathrm{G}()=1)$. & $(0.39)^{*}$ & $(0.13)^{*}$ & $(0.10)^{* * *}$ \\
& -0.01 & -0.03 & -0.11 \\
Constant $(\mathrm{G}()=0)$. & $(0.03)$ & $(0.02)$ & $(0.04)^{* * *}$ \\
& -0.01 & -0.00 & 0.11 \\
Constant, NL & $(0.02)$ & $(0.01)$ & $(0.04)^{* * *}$ \\
& 0.00 & -0.03 & -0.22 \\
Estimated Transition Parameter $(\varphi)$ & $(0.05)$ & $(0.03)$ & $(0.07)^{* * *}$ \\
& 5.37 & 11.93 & 1.00 \\
Estimated Threshold $(\tau)$ & $(3.05)^{*}$ & $(9.67)$ & $(0.35)^{* * *}$ \\
& 0.54 & 0.50 & 0.34 \\
Half-Life (G(.)=1) & $(0.14)^{* * *}$ & $(0.07)^{* * *}$ & $(0.09)^{* * *}$ \\
Half-Life (G(.)=0) & & & \\
Threshold Variable & 0.80 & 2.20 & 1.61 \\
Sigma-squared & - & 11.20 & - \\
R-squared & & & \\
Observations & $\mathrm{GPD}$ & $\mathrm{GED}$ & $\mathrm{NEL}$ \\
& 0.0125 & 0.0132 & 0.0144 \\
\hline \hline
\end{tabular}

Notes: The dependent variable is the change in the logarithm of the real effective exchange rate. Half-life is measured in years. GPD, GED, and NEL denote gross public debt, gross external debt liabilities, and net external liabilities respectively. Convergence of estimates is always achieved within 500 iterations. Estimated by nonlinear least squares. GNR-based test for autoregressive errors shows no trace of serial correlation across all specifications.

Asterisks $* * * * *, *$ indicate significance at $1 \%, 5 \%$ and $10 \%$ levels respectively. 
Table 7: Standard Deviations

\begin{tabular}{lcc}
\hline \hline & (1) & (2) \\
\hline d(GAP) & 0.091 & 0.159 \\
d(NEER) & 0.584 & 0.298 \\
d(INF DIF) & 0.576 & 0.333 \\
Regime & $\omega_{i t}<\tau$ & $\omega_{i t} \geq \tau$ \\
Observations & 156 & 64
\end{tabular}

Notes: $\mathrm{d}(\mathrm{NEER})$ is the change in the logarithm of the nominal effective exchange rate, $\mathrm{d}(\mathrm{INF}$ DIF) is the inflation differential with respect to trading partners, and d(GAP) is the change in the misalignment. Gross public debt is used as the threshold variable $\omega_{i t}$. 
Table 8: Real Exchange Rate Variance

\begin{tabular}{|c|c|c|c|c|}
\hline & (1) & (2) & (3) & (4) \\
\hline $\mathrm{d}(\mathrm{NEER})$ & 0.72 & 0.81 & 0.71 & 0.82 \\
\hline $\mathrm{d}(\mathrm{INF}$ DIF) & $\begin{array}{l}0.73 \\
(0.05)^{* * *}\end{array}$ & $\begin{array}{l}0.92 \\
(0.06) * * *\end{array}$ & $\begin{array}{l}0.73 \\
(0.05)^{* * *}\end{array}$ & $\begin{array}{l}0.96 \\
(0.06)^{* * *}\end{array}$ \\
\hline L.d(NEER) & $\begin{array}{l}-0.12 \\
(0.05)^{* * *}\end{array}$ & $\begin{array}{l}-0.10 \\
(0.04)^{* *}\end{array}$ & $\begin{array}{l}-0.15 \\
(0.08)^{*}\end{array}$ & $\begin{array}{l}-0.32 \\
(0.10)^{* * *}\end{array}$ \\
\hline L.d(INF DIF) & $\begin{array}{l}-0.13 \\
(0.04)^{* * *}\end{array}$ & $\begin{array}{l}-0.13 \\
(0.04)^{* * *}\end{array}$ & $\begin{array}{l}-0.15 \\
(0.07)^{* *}\end{array}$ & $\begin{array}{l}-0.36 \\
(0.11)^{* * *}\end{array}$ \\
\hline L.d(GAP) & & & $\begin{array}{l}0.03 \\
(0.07)\end{array}$ & $\begin{array}{l}0.27 \\
(0.11)^{* *}\end{array}$ \\
\hline R-squared & 0.62 & 0.90 & 0.62 & 0.91 \\
\hline MR-squared (NEER) & 0.61 & 0.84 & 0.60 & 0.85 \\
\hline MR-squared (INF DIF) & 0.56 & 0.78 & 0.56 & 0.80 \\
\hline $\begin{array}{l}\text { Regime } \\
\text { Observations }\end{array}$ & $\begin{array}{l}\omega_{i t}<\tau \\
156\end{array}$ & $\begin{array}{l}\omega_{i t} \geq \tau \\
64\end{array}$ & $\begin{array}{l}\omega_{i t}<\tau \\
156\end{array}$ & $\begin{array}{l}\omega_{i t} \geq \tau \\
64\end{array}$ \\
\hline
\end{tabular}

Notes: The dependent variable is the change of the real effective exchange rate misalignment. $\mathrm{d}(\mathrm{NEER})$ is the change in the logarithm of the nominal effective exchange rate, $d$ (INF DIF) is the inflation differential with respect to trading partners. L.VAR is the lag of variable VAR. Gross public debt is used as the threshold variable $\omega_{i t}$. Estimated by pooled OLS. GNR-based test for autoregressive errors shows no trace of serial correlation across all specifications.

Asterisks ***,***, indicate significance at $1 \%, 5 \%$ and $10 \%$ levels respectively. 


\section{Appendices}

\section{A A Two-Sector Open Economy Model}

\section{Firms}

Consider an open economy that produces two goods, tradables and nontradables. Outputs are given by Cobb-Douglas production functions of the labor and capital employed, with the non-traded sector requiring a fixed factor (normalized to 1) in addition

$$
Y_{T}=A_{T} L_{T}^{\alpha_{L}} K_{T}^{\alpha_{K}}
$$

and

$$
Y_{N}=A_{N} L_{N}^{\beta_{L}} K_{N}^{\beta_{K}}
$$

where $\beta_{L}+\beta_{K}<1, \alpha_{L}+\alpha_{K}=1$ and the $A_{i}$ are productivity shifters. Both labor and capital are mobile intersectorally. As is standard, we assume international mobility of capital, but immobility of labor. Because of the fixed factor, the nontraded sector generates non-zero profits that are distributed to consumers. ${ }^{34}$ The price of the traded goods is equal to the world price of 1 .

The world interest rate determines the capital to labor ratio in the traded sector, which in turn determines wages in terms of traded goods prices in both sectors. Using the firstorder conditions, it can be shown that the capital to labor ratio in traded and nontraded sectors are proportional.

\section{Consumers}

Consumers maximize the present discounted value of the instantaneous utility function $U=\ln C-(1+\psi)^{-1} L^{1+\psi}$ subject to the flow budget constraint present in each period

$$
\Delta B=r B+r\left(K_{T}+K_{N}\right)+w(1-\tau)\left(L_{T}+L_{N}\right)-P C+\Pi_{N}
$$

where $B$ is an internationally trade bond that pays the fixed rate $r, \Pi_{N}=\left(1-\beta_{L}-\beta_{K}\right) P_{N} Y_{N}$ is the aggregate profit in the non-traded sector and $\tau$ is the rate of distortionary taxation. The rate of capital depreciation is set equal to zero. ${ }^{35}$ We further assume a unitary elasticity of substitution between traded and nontraded goods.

\footnotetext{
${ }^{34}$ For the standard treatment without a fixed factor see Obstfeld and Rogoff (1996).

${ }^{35}$ Since our interest is in steady-state relations, a zero depreciation rate of the capital stock allows us to disregard the investment process altogether.
} 
The intratemporal labor-consumption optimality condition sets the ratio between marginal utilities of effort and consumption equal to the real wage

$$
L^{\psi}=\frac{1}{C} \frac{w}{P}(1-\tau)
$$

Furthermore, the optimal allocation of consumption between traded and non-traded goods requires that

$$
C_{N}=\gamma P_{N}^{\gamma-1} C \text { and } C_{T}=(1-\gamma) P_{N}^{\gamma} C
$$

where $P=P_{N}^{\gamma}$ and $C=(1-\gamma)^{\gamma-1} \gamma^{-\gamma} C_{T}^{1-\gamma} C_{N}^{\gamma}$. Note that $P$ is the welfare-based price index consistent with the definition for $C$. Assuming that the price of nontraded goods in the rest of the world is fixed and normalized to 1 , changes in $P$ correspond to changes in the real exchange rate.

\section{Government}

The government consumes both traded and nontraded goods. To finance spending, it can borrow or tax labor income. Thus, the flow budget constraint facing the government takes the following form

$$
\Delta D+\tau w L=r D+G_{T}+P_{N} G_{N}
$$

where $D$ is the level of public debt, and $G_{T}$ and $G_{N}$ are the levels of public consumption of the traded and nontraded goods respectively.

\section{Equilibrium}

Equations characterizing the equilibrium in the labor market and nontraded goods market are given by

$$
L=L_{N}+L_{T}
$$

and

$$
Y_{N}=C_{N}+G_{N}
$$

Combining equations (A.6) and (A.3) along with the firms' first order conditions we derive the following equation describing equilibrium in the traded goods market

$$
\Delta N=r N+Y_{T}-C_{T}-G_{T}
$$

where $N=B-D$ is the net foreign asset position. 


\section{Solution}

Table A at the end of this appendix summarizes the system. Our primary interest is in the long-run relation between the real exchange rate, productivities, net foreign asset position, public debt and fiscal spending. Accordingly, we first solve the system for the benchmark steady state in which the net foreign asset position, public debt, fiscal spending and taxes are set equal to zero, while sectoral productivity levels are normalized to one. It is possible to show that equilibrium labor in the benchmark steady state is given by

$$
\bar{L}=\left((1-\gamma) \alpha_{L}+\gamma \beta_{L}\right)^{\frac{1}{1+\psi}}
$$

while in the traded and non-traded sectors by $\bar{L}_{N}=\theta \bar{L}$ and $\bar{L}_{T}=(1-\theta) \bar{L}$, where $\theta=\gamma \beta_{L}\left((1-\gamma) \alpha_{L}+\gamma \beta_{L}\right)^{-1}$.

Defining $\hat{N}=(B-D) \bar{Y}_{T}^{-1}, \hat{D}=D \bar{Y}_{T}^{-1}, \hat{G}_{i}=G_{i} \bar{Y}_{i}^{-1}$ for $i=T, N$ and all other $\hat{X}=(X-\bar{X}) \bar{X}^{-1}$ as percentage deviations from corresponding steady state values $\bar{X}$, we next log-linearize the general system around the aforementioned benchmark. The first equation of interest is the linearized version of the long-run government constraint

$$
\tau=r \frac{1-\theta}{\alpha_{L}} \hat{D}+\frac{1-\theta}{\alpha_{L}} \hat{G}_{T}+\frac{\theta}{\beta_{L}} \hat{G}_{N}
$$

which states that in the long run, for a given level of public spending, higher public debt is associated with a higher tax rate.

The second equation of interest is that of the real exchange rate given by

$$
\begin{aligned}
\hat{P}= & -\frac{\gamma \beta_{F}}{1+\psi} \tau+\frac{\psi(1-\theta) \gamma \beta_{F}}{1+\psi} r \hat{N}+\frac{\gamma\left(1-\beta_{K}\right)}{\alpha_{L}} \hat{A}_{T}-\hat{A}_{N} \\
& +\frac{(1+\psi(1-\theta)) \gamma \beta_{F}}{1+\psi} \hat{G}_{N}-\frac{\psi(1-\theta) \gamma \beta_{F}}{1+\psi} \hat{G}_{T}
\end{aligned}
$$

where $\beta_{F}=1-\beta_{L}-\beta_{K}$. Equation (A.12) shows that a positive net foreign asset position, generating a positive wealth transfer from the rest of the world, is associated with an appreciated exchange rate. Higher productivity in the traded sector or lower productivity in the nontraded sector causes an appreciation of the real exchange rate via the BalassaSamuelson mechanism. Regarding public consumption, for a given level of the tax rate, higher government spending on nontraded goods or lower expenditure on traded goods is linked to a rise in the real exchange rate.

Finally, equations (A.11) and (A.12) show that higher public debt is correlated with more depreciated exchange rates. To see why this happens, note that the relative price 
of nontraded goods is determined by the intersection of relative demand and supply curves. More specifically, relative demand and relative supply are given by

$$
R D=-\hat{P}_{N}+\hat{G}_{N}-\hat{G}_{T}+r \hat{N}
$$

and

$$
R S=\hat{Y}_{N}-\hat{Y}_{T}
$$

where

$$
\hat{Y}_{T}=\frac{1}{\alpha_{L}} \hat{A}_{T}+\hat{L}_{T}, \hat{Y}_{N}=\hat{A}_{N}+\frac{\beta_{K}}{\alpha_{L}} \hat{A}_{T}+\left(\beta_{L}+\beta_{K}\right) \hat{L}_{N}
$$

and equilibrium labor supply is governed by

$$
\begin{aligned}
\hat{L} & =\frac{\theta}{1+\psi} \hat{G}_{N}+\frac{1-\theta}{1+\psi} \hat{G}_{T}-\frac{1-\theta}{1+\psi} r \hat{N}-\frac{1}{1+\psi} \tau \\
\hat{L}_{T} & =\frac{1+\psi \theta}{1+\psi} \hat{G}_{T}-\frac{\psi \theta}{1+\psi} \hat{G}_{N}-\frac{1+\psi \theta}{1+\psi} r \hat{N}-\frac{1}{1+\psi} \tau \\
\hat{L}_{N} & =\frac{1+\psi(1-\theta)}{1+\psi} \hat{G}_{N}-\frac{\psi(1-\theta)}{1+\psi} \hat{G}_{T}+\frac{\psi(1-\theta)}{1+\psi} r \hat{N}-\frac{1}{1+\psi} \tau
\end{aligned}
$$

With these equations in mind, the reasoning behind the negative link becomes more transparent. In the long run, for a given level of public spending, high public debt is associated with a higher tax rate. A high tax rate, in turn, reduces aggregate labor supply proportionally in both sectors. Due to the fixed factor of production in the nontraded sector however, contraction in the supply of nontraded goods is smaller than the contraction in the supply of traded goods. This increases the relative supply of nontraded goods causing the relative price of nontraded goods to decline. 
Table A: The System

\begin{tabular}{ll}
\hline \hline$Y_{T}=A_{T} L_{T}\left(\frac{K_{T}}{L_{T}}\right)^{1-\alpha}$ & $Y_{N}=A_{N} L_{N}^{\beta_{L}+\beta_{K}}\left(\frac{K_{N}}{L_{N}}\right)^{\beta_{K}}$ \\
$\alpha A_{T}\left(\frac{K_{T}}{L_{T}}\right)^{1-\alpha}=w$ & $(1-\alpha) A_{T}\left(\frac{K_{T}}{L_{T}}\right)^{-\alpha}=r$ \\
$\beta_{L} P_{N} A_{N} L_{N}^{\beta_{L}+\beta_{K}-1}\left(\frac{K_{N}}{L_{N}}\right)^{\beta_{K}}=w$ & $\beta_{K} P_{N} A_{N} L_{N}^{\beta_{L}+\beta_{K}-1}\left(\frac{K_{N}}{L_{N}}\right)^{\beta_{K}-1}=r$ \\
$L^{\psi}=\frac{1}{C} \frac{w}{P}(1-\tau)$ & $C_{T}=\frac{1-\gamma}{\gamma} P_{N} C_{N}$ \\
$P=P_{N}^{\gamma}$ & $C=\frac{C_{T}^{1-\gamma} C_{N}^{\gamma}}{(1-\gamma)^{1-\gamma} \gamma^{\gamma}}$ \\
$Y_{T}=C_{T}+G_{T}-r N$ & $Y_{N}=C_{N}+G_{N}$ \\
$L=L_{N}+L_{T}$ & $\tau w L=r D+G_{T}+P_{N} G_{N}$ \\
\hline
\end{tabular}

\section{B Country List}

Primary sample: Argentina, Brazil, Chile, Mexico, Peru, Indonesia, Malaysia, Philippines, Thailand, Korea.

Trading partners: United States, United Kingdom, Austria, Belgium, Denmark, France, Germany, Italy, Netherlands, Norway, Sweden, Switzerland, Canada, Japan, Finland, Greece, Ireland, Portugal, Spain, Turkey, Australia, New Zealand, South Africa, India, Singapore, China. 